\title{
Explaining Adherence to HAART among Patients Living with HIV/AIDS in Nigeria: Behavioral Theory Analysis
}

Afe $\mathrm{AJ}^{1 *}$, Motunrayo ${ }^{2}$ and Ogungbade $\mathbf{G O}^{3}$

${ }^{1}$ Equitable Health Access Initiative, Nigeria

${ }^{2}$ Babcock University, Nigeria

${ }^{3}$ Adeleke University, Nigeria

\begin{abstract}
Background: The number of Nigerians infected with the HIV infection in 2016 was about 3 million, which was the second highest burden globally and accounted for $9 \%$ of the worldwide burden of the HIVIAIDS. The country ART (antiretroviral therapy) programme which commenced in 2001 had adult coverage of $48.3 \%$ in 2014. Effectiveness of the antiretroviral drug regimens requires a very good level of adherence $(95 \%)$ to suppress viral replication. Despite all the strategies to address the adherence barriers to HAART (highly active antiretroviral therapy), the problems of poor adherence are ever-present. Factors determining adherence to HAART drug regimens have been studied in various population but little is known on this subject among PLHIV (people living with HIV) in Nigeria. Identifying and overcoming the factors that reduce adherence to combination antiretroviral agents is of utmost importance for prolonged viral load suppression.
\end{abstract}

Very few of the strategies developed to mitigate the challenges of non-adherence were based on the theories of health behavior. However, behavioural theories, if adopted, could assist in the development of more effective interventions to improve treatment adherence. This cross-sectional study was conducted to explain the dynamics of HAART adherence among Nigerians living with HIVIAIDS; using behaviour change theories such as the Theory of Planned Behavior (TPB) and Health Belief Model (HBM).

Methods: This was a questionnaire-based study using closed ended-questionnaires administered by the on the 225 participants.

Findings: There were more female $(181,80.40 \%)$ than male $(19.6 \%)$ living with HIV infection among the respondents. More than half, $(139,61.7 \%)$, of the respondents were married while less than a fifth $(66 ; 29 \%)$ were singles About $96 \%$ of the respondents were literate with $2.7 \%$ illiteracy rate. Employment rate was also more than half (59\%) while the unemployed rate was about $31.6 \%$. Most $(202,89.8 \%)$ were of the Christianity faith TPB model factors such as the ability to set realistic goals and objectives with respect to medication adherence and meet such goals did not have any significant association with adherence (P 0.001) among the PLHIV. Likewise other TPB factors like determination and self-discipline to adhere to medications (HAART) did not have statistical association with HAART adherence. On the other hand, Health Believe Model (HBM) components such as the believes that adherence to HAART improves HIV patent's health condition $(P=0.004)$,adherence to HIV medication is feasible in the Nigerian context $(P=0.00)$, refusal to adhere to HAART is a serious health risk for the HIV patient $(P=0.00)$, non-adherence to HAART is life threatening for the HIV patient $(P=0.00)$, non-adherence to HAART can lead to AIDS faster $(P=0.00)$ and the consequences of non-adherence to HAART are severe $(P=0.00)$ all show significant statistical association with HAART adherence .Also significant statistical association was found between HAART adherence and other health believes like adherence to HAART is beneficial $(P=0.00)$.

Conclusion: Unlike the theory of planned behaviour, health believes Model was most suited to explaining or predicting patterns of HAART adherence behaviour among Nigerians PLHIV. However, for the model to be most effective it would need to be integrated with other models that take into account the environmental context and recommend strategies for change.

Keywords: HIV; HBV; PMTCT; Vertical transmission; ART (antiretroviral therapy)

\section{Introduction}

The population of Nigerians living with the HIV infection was about 3 million in 2016, which was the second highest in the world after south Africa and represent $9 \%$ of the worldwide burden of the HIV/AIDS, Nigeria accounted for about one third of all new pediatric HIV in the 21 HIV priority countries in sub-Saharan Africa: The largest number from any country [1-3]. It also had the highest population of children acquiring HIV infection; about 60, 000 in 2012 and this figure has remained largely the same since 2009 [4]. Nigeria has generalized HIV epidemic with wide differences in the prevalence across the country. The HIV prevalence has declined over the years, from 5.8 percent in 2001 to 4.6 percent in $2008,4.1 \%$ in 2010 and $3.0 \%$ in 2014 [5]. Incidence of new
HIV infections in Nigeria are driven by factors such as low perceptions of personal HIV risk, multiple sexual partnerships, transactional and intra-generational sex, poor treatment services for sexually transmitted

*Corresponding author: Abayomi Joseph Afe, Equitable Health Access Initiative P.O. Box 10047, GPO, Marina, Lagos, Nigeria, Tel: 234-8023368959; E-mail: abayomiafe@yahoo.com

Received July 22, 2017; Accepted August 02, 2017; Published August 09, 2017

Citation: Afe AJ, Motunrayo, Ogungbade GO (2017) Explaining Adherence to HAART among Patients Living with HIVIAIDS in Nigeria: Behavioral Theory Analysis. J AIDS Clin Res 8: 718. doi: 10.4172/2155-6113.1000718

Copyright: (C) 2017 Afe AJ, et al. This is an open-access article distributed unde the terms of the Creative Commons Attribution License, which permits unrestricted use, distribution, and reproduction in any medium, provided the original author and source are credited. 
infections (STIs) and inadequate access to quality health care services. Other contributing factors include gender inequalities and inequities, poverty and HIV/AIDS stigma and discrimination [6].

The Nigerian national ART (antiretroviral therapy) programme started in 2001 with 25 tertiary hospitals and targeted 10,000 adults and 5,000 children. However, following the 3 by 5 WHO initiative, the target was reviewed to achieve universal access to ART by 2010. As at 2014, ART coverage among children consistently remained low when compared to adults. Generally, there is an increase in ART coverage from $10.2 \%$ in 2010 to $20.7 \%$ in 2014 for children under 15 years. The adult coverage showed a progressive increase from $27.6 \%$ in 2010 to $48.3 \%$ in 2014. As at 2014, the National ART program covered 747,382 (44\%) out of the estimated 1,670,016 persons (adults and children) estimated to need ART by December, 2014. This shows a very poor achievement when compared with the national target sustainable scaleup of ART coverage [6,7]. The use of antiretroviral therapy (ART) has allowed people infected with HIV infection to live longer, healthier lives, slowing disease progression and preventing opportunistic diseases. Generally, most medications used in treating chronic disease conditions are less effective without perfect adherence. Common estimates of drug adherence in most chronic illness are from $20 \%$ to $80 \%$, averaging $50 \%$, and decreasing over the duration of the treatment [8]. Effectiveness of the antiretroviral drug regimens requires at least a very good level of adherence. This is so because good adherence ensures that the blood therapeutic level of the ARV is maintained to suppress viral replication. The consequences of poor adherence include inadequate viral suppression leading to greater probability of transmission, immunologic and clinical failure thus increasing the susceptibility to opportunistic infections, disease progression which increase HIV-related mortality and morbidity. Other complications are increased health care costs, emergence of drug resistance and limited future treatment options. In many studies, perfect adherence to ART (95\%) has led to dramatic reductions in viral load to undetectable levels, compared to smaller viral load reductions seen when doses were missed [9]. Small viral load reductions can lead to increased risk of viral mutation and drug resistance. Several estimates of adherence level to antiretroviral therapy were reported to fall below the $95 \%$ adherence recommended to maintain long-term viral suppression [10-13].

\section{Highly active antiretroviral therapy (HAART)}

This is a combination of at least three antiretroviral drugs from at least two different classes of ARV (antiretroviral drugs) which act on at least two different points in the HIV life cycle. Typically, a backbone of an NNRTI (non-nucleoside reverse transcriptase inhibitors) or a PI (protease inhibitors) can be combined with 2 NRTIs (nucleoside reverse transcriptase inhibitors). The choice of drugs to use in each class is based on availability, accessibility, affordability, efficacy and ease of administration of antiretroviral drugs. Monotherapy or dual therapy is not recommended for treatment because of the increased risks of development of drug resistance. Scientists have observed that multiple factors influenced adherence to medication among patients with chronic diseases in general [13]. Poor treatment adherence remains a challenge to the control of many infectious diseases such as tuberculosis and human immunodeficiency virus (HIV) infection.

Non-adherence is multifactorial and differs between patients. Successful long-term treatment of HIV/AIDS requires at least $95 \%$ adherence to the antiretroviral therapy (HAART) required for viral suppression required to keep people living with HIV/AIDS (PLHIV) in good health and prevent emergence of drug-resistant HIV variants that could lead to regimen failure and limit options for future therapy
[14-16]. Despite all the strategies to address the adherence barriers to prescribed HAART drug regimens to manage HIV/AIDS, the problems of inadequate observance are ever-present [17]. Among people living with HIV, it is almost impossible to predict which of them will best adhere to antiretroviral therapy (ART) medication as preconceived ideas about who will be adhering and who will not are often wrong. Factors determining adherence to ARV drug regimens have [3] been studied in various population but little is known on this subject among people living with HIV/AIDS in Nigeria.

Identifying and overcoming the factors that reduce adherence to combination antiretroviral agents is of utmost importance for prolonged viral load suppression. Very few of the many interventions developed to address the challenges of non-adherence are based on behaviour theories. These theories of health behaviour can be used to develop more effective interventions to promote ART adherence and can be used to assess the possibility of extending other interventions to different health issues and settings. This cross-sectional study aimed to use behavior change theories applicable to long-term treatment adherence, such as the Theory of Planned Behavior (TPB) and Health Belief Model (HBM) as theoretical framework and a self-addressed tool to explain the dynamics of HAART adherence among Nigerians living with HIV/AIDS; assess the evidence for their effectiveness of the theories in predicting behavior change; and examine the implications of these findings for developing strategies to improve HIV/AIDS medication adherence.

\section{The theory of planned behaviour}

The theory of planned behaviour (TPB) is a very commonly used behaviour theory. It adopts a cognitive method of explaining behaviour which centres on individuals' attitudes and beliefs [18].TPB started as the theory of reasoned action in 1980.The theory of reasoned action posited intention as the best predictor of behaviour. This theory was used to predict an individual's intention to engage in a behavior at a specific time and place. Though intention is an outcome of the combination of attitudes towards a behaviour. TPB is composed of six constructs which collectively represent a person's control over a behavior [19,20] (Figure 1).

- It presumes the availability of opportunities and 1. AttitudesThis is the degree to which a person has a favorable or unfavorable evaluation of the behavior of interest. It entails a consideration of the outcomes of performing the behavior.

- Behavioural intention - These are the motivational factors

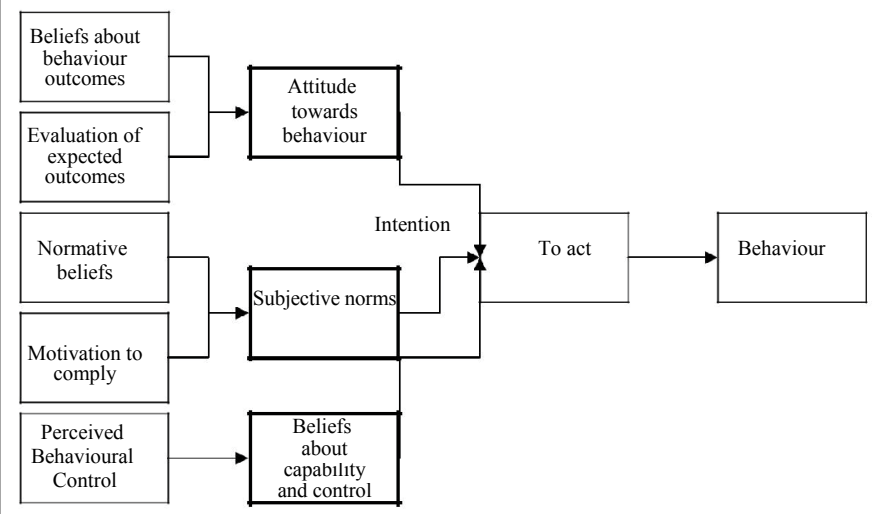

Figure 1: The theory of planned behavior [38]. 
that influence a given behaviour; the stronger the intention to perform the behavior, the more likely the behaviour will be performed.

- Subjective norms - This refers to a person's beliefs about whether peers and people of importance to the person think he or she should engage in the behavior and their inclination to comply with these.

- Social norms - This refers to the customary codes of behavior in a group of people or larger cultural context and could be normative, or standard.

- Perceived power - This is the perceived presence of factors that may facilitate or hinder performance of a behavior. Perceived power determines a person's perceived behavioral control over these factors.

- Perceived behavioral control - Also known as self-efficacy. It is the perception of the ease or difficulty of performing the behavior of interest. This perception differs across situations and actions and can lead to a person having different perceptions of behavioral control in different situations. This construct when added to the theory of reasoned action caused its transformation to the theory of planned behavior [21,22].

\section{Limitations of the theory of planned behaviour}

- Resources needed for a successful performance of the desired behaviour, regardless of the intention.

- It does not take into account other variables that influence behavioural intention and motivation, such as fear, threat, mood, or past experience.

- Likewise, environmental or economic factors that may influence a person's intention to perform behaviour are not taken into consideration by this theory.

- It presumes that behavior is the result of a linear decisionmaking process that does not can change over time.

- The perceived behavioral control component of this theory doesn't say anything about actual control over behavior.

- The theory does not address the time frame between "intent" and "behavioral action".

\section{The health belief model}

The Health Belief Model (HBM) was developed in the early 1950s to comprehend the failure of some people to accept disease prevention strategies or screening tests for the early detection of disease. Other uses of HBM include understanding of patients' responses to symptoms and compliance with medical treatments. The model postulates that behaviour is determined by beliefs about threats to an individual's wellbeing and the effectiveness and outcomes of particular actions or behaviuor [23-27]. In other words, the model suggests that belief in a personal threat of an illness or disease together with belief in the effectiveness of the recommended health behavior or action will predict the likelihood of adoption of the behaviour. Conversely, when a person perceives a threat is not serious or himself as unsusceptible to it, he is unlikely to adopt mitigating behaviours. Same effect is seen with perceived low benefits and high costs of the behaviour There are six constructs of the HBM; the first four were the original tenets while the last two were recent additions.
- Perceived susceptibility - This is the subjective perception of the risk of acquiring an illness or disease. There is wide variation in this perception of personal vulnerability

- Perceived severity - This refers to a person's feelings of the danger or complications of contracting an illness or disease. This perception varies with different persons and is influenced by the medical consequences (e.g. death, disability) and social consequences (e.g. family life, social relationships) associated with the diseases.

- Perceived benefits - This refers to a person's perception of the effectiveness of various measures available to reduce the risks of illness to cure disease. The choice of preventive or curative measures a person adopts depends on consideration and evaluation of both perceived susceptibility and perceived benefit of such actions, so that health action perceived as beneficial are readily adopted.

- Perceived barriers - This refers to having a feeling of presence of obstacles to performing a recommended health action. This feeling varies widely with people and leads to a cost/ benefit analysis in which the person weighs the effectiveness of the actions against the perceptions that it may be expensive, may have side effects, may be painful, time-consuming, or inconvenient.

- Cue to action - This is the stimulus needed to initiate the decision-making process to accept a recommended health action. These cues can be internal (e.g. chest pains, wheezing, etc.) or external (e.g. advice from others, illness of family member, newspaper article, etc.). These cues influence the perception of threat and can cause a change in behaviour or maintain.

- Self-efficacy - This defines the level of a person's confidence in his or her ability to successfully perform a behavior. It is associated with many behavioral theories as it directly determines whether a person performs the desired behavior. Both perceived susceptibility also known as perceived vulnerability and perceived severity are combined as perceived threat which form the core of the HBM as it is linked to a person's 'readiness' to take action. The self-efficacy is a key component of the model.

\section{Some limitations of health belief model include the following}

- It does not consider individual's attitudes, beliefs or other personal determinants that dictate acceptance of a health behavior.

- It disregards habitual behaviors such as smoking which may influence decision-making process to accept a recommended action

- Non-health related behaviors such as social acceptability are not factor into this model

- Environmental or economic factors that may prohibit or promote the recommended action are not considered.

- It assumes there is an access to equal amounts of information on the illness or disease.

- It presumes that cues to action are prevalent in encouraging people to act and that "health" actions are the main goal in the decision-making process. 


\section{Methods}

\section{Study population}

Persons living with HIV/AIDS infection.

\section{Sampling areas}

Adult ART clinics at public health facilities in Ondo and Ekiti southwestern states.

\section{Sample and sampling technique}

Convenient sampling.

\section{Sample size}

The sample size of 225 was calculated using online raosoft formula: Sample size $\mathrm{n}=\mathrm{N} \mathrm{x} /((\mathrm{N}-1) \mathrm{E} 2+\mathrm{x}))(17)$.

\section{Sampling method}

Non-probability convenient sampling was used to select the sample size of into $225 \mathrm{HIV}$ infected persons.

\section{Study instrument design}

Interviewer administered structured questionnaire. The high reliability and validity of the questionnaire content was evaluated in a pilot study and by expert's opinions.

\section{Inclusion criteria}

To be eligible to participate in this survey, potential participants were required to:

- HIV infected patients enrolled in ART clinics.

- $\quad$ Adults not less than 18 years of age.

- $\quad$ Provide voluntary informed consent.

\section{Exclusion criteria}

Participation was restricted from individuals who were:

- $\quad$ Not mentally capable of providing response.

- Previously sampled by the same questionnaire.

\section{Data analysis}

Analysis of the data collected in this study was done with statistical package for the social sciences (SPSS) for windows version 20.0 software (SPSS Inc.; Chicago, IL, USA). Tables of frequency counts were generated for all variables and statistical test of significance was performed with chi-square test. Significance was fixed at $\mathrm{P}<0.05$.

\section{Study weaknesses}

1. The study findings are representative of those who complete the survey and may be difficult to extend to the Nigeria resident as a whole, being a heterogeneous population.

2. Response bias.

3. Study incapable of estimating any causal association.

4. Selection bias as persons who refused to participate in the survey may have differed opinions from respondents with respect to Adherence to HAART.

5. Information bias due to the use of interviewer administered questionnaires that could lead to recall bias or interviewer's bias.

\section{Study strength}

(a) The use of theories of health behaviour to analyse adherence to HAART in Nigeria settings is a novel idea.

(b) The ability to identify HAART adherence risk determinants/ factors in Nigerian resident sample, which have neither been studied nor documented as far as we know.

\section{Ethical consideration}

Ethical approval obtained with protocol number (ERC/2016/03/02/10B).

\section{Results}

\section{Socio-demographic characteristics of respondents}

Table 1 showed that there were more female $(181,80.40 \%)$ than male (19.6\%) living with HIV infection among the respondents. More than half $(139,61.7 \%)$ of the respondents were married while less than a fifth $(66 ; 29 \%)$ were singles About $96 \%$ of the respondents were literate with $2.7 \%$ illiteracy rate. Employment rate was also more than half (59\%) while the unemployed rate was about 31.6\%. Most (202, $89.8 \%$ ) were of the Christianity faith.

\section{Explaining adherence with behavioural theory (TPB) (Table 2)}

Of the 225 respondents, about $93 \%$ of those who do not adhere to HAART and $90 \%$ of those who adhere to HAART can set realistic goals/objectives for HAART adherence. Thus ability to set realistic

\begin{tabular}{|c|c|c|}
\hline Gender & Frequency & Percent \\
\hline Female & 181 & 80.4 \\
\hline Male & 44 & 19.6 \\
\hline Total & 225 & 100.0 \\
\hline Marital status & Frequency & Percent \\
\hline Co-Habiting & 3 & 1.3 \\
\hline Divorced & 4 & 1.8 \\
\hline Married & 136 & 60.4 \\
\hline Separated & 4 & 1.8 \\
\hline Single & 66 & 29.3 \\
\hline Widowed & 12 & 5.3 \\
\hline Total & 225 & 100.0 \\
\hline Highest educational level & Frequency & Percent \\
\hline $\begin{array}{l}\text { No Formal } \\
\text { Education }\end{array}$ & 6 & 2.7 \\
\hline Primary & 36 & 16.0 \\
\hline Secondary School & 150 & 66.7 \\
\hline Bachelor/HND/OND & 23 & 10.2 \\
\hline Postgraduate & 10 & 4.4 \\
\hline Total & 225 & 100.0 \\
\hline Employment Status & Frequency & Percent \\
\hline Employed & 133.0 & 59.1 \\
\hline Retired & 4 & 1.8 \\
\hline Student & 17 & 7.6 \\
\hline Unemployed & 71 & 31.6 \\
\hline Total & 225 & 100.0 \\
\hline Religion & Frequency & Percent \\
\hline Christianity & 202 & 89.8 \\
\hline Muslim & 23 & 10.2 \\
\hline Total & 225 & 100.0 \\
\hline
\end{tabular}

Table 1: Socio-demographic characteristics of respondents. 


\begin{tabular}{|c|c|c|c|c|c|c|c|}
\hline & & & \multicolumn{4}{|c|}{ HAART Adherence } & \multirow[t]{2}{*}{ Total } \\
\hline & & & No & Percent & Yes & Percent & \\
\hline \multirow{3}{*}{\multicolumn{2}{|c|}{$\begin{array}{l}\text { I can set realistic goals/objectives for } \\
\text { HAART adherence }(P=0.263)\end{array}$}} & Don't Know & 2 & $5 \%$ & 10 & $5 \%$ & 12 \\
\hline & & No & 1 & $3 \%$ & 9 & $5 \%$ & 10 \\
\hline & & Yes & 37 & $93 \%$ & 166 & $90 \%$ & 203 \\
\hline \multicolumn{3}{|l|}{ Total } & 40 & $100 \%$ & 185 & $100 \%$ & 225 \\
\hline & & & \multicolumn{4}{|c|}{ HAART Adherence } & \\
\hline \multirow{4}{*}{\multicolumn{2}{|c|}{$\begin{array}{l}\text { I can meet set realistic goals/objectives } \\
\text { for HAART Adherence }(P=0.994)\end{array}$}} & & Yes & Percent & No & Percent & \\
\hline & & Don't Know & 1 & $2.5 \%$ & 12 & $6 \%$ & 13 \\
\hline & & No & 1 & $2.5 \%$ & 7 & $4 \%$ & 8 \\
\hline & & Yes & 38 & $95 \%$ & 166 & $90 \%$ & 204 \\
\hline \multirow{3}{*}{\multicolumn{3}{|c|}{ Total }} & 40 & 100 & 185 & $100 \%$ & 225 \\
\hline & & & \multicolumn{4}{|c|}{ HAART Adherence } & \multirow[t]{2}{*}{ Total } \\
\hline & & & No & Percent & Yes & Percent & \\
\hline \multirow{7}{*}{\multicolumn{2}{|c|}{$\begin{array}{l}\text { How determined are you to adhere } \\
\text { medications? }(P=0.953)\end{array}$}} & Not at all determined & 0 & $0 \%$ & 1 & $1 \%$ & 1 \\
\hline & & Not so determined & 0 & $0 \%$ & 3 & $2 \%$ & 3 \\
\hline & & No response & 8 & $19 \%$ & 21 & $11 \%$ & 29 \\
\hline & & Determined & 10 & $24 \%$ & 70 & $38 \%$ & 80 \\
\hline & & I don't know & 2 & $5 \%$ & 4 & $2 \%$ & 6 \\
\hline & & Not so determined & 0 & $0 \%$ & 3 & $2 \%$ & 3 \\
\hline & & Very determined & 22 & $52 \%$ & 81 & $44 \%$ & 103 \\
\hline \multirow{3}{*}{\multicolumn{3}{|c|}{ Total }} & 42 & $100 \%$ & 183 & $100 \%$ & 225 \\
\hline & & & \multicolumn{4}{|c|}{ HAART Adherence } & \multirow[t]{2}{*}{ Total } \\
\hline & & & No & Percent & Yes & Percent & \\
\hline \multirow{5}{*}{$\begin{array}{l}\text { I have self-discipline to adhere to } \\
\text { HAART }(P=0.655)\end{array}$} & \multicolumn{2}{|c|}{ Don't know } & 2 & $5 \%$ & 8 & $4 \%$ & 10 \\
\hline & \multicolumn{2}{|c|}{ Agree } & 14 & $35 \%$ & 89 & $48 \%$ & 103 \\
\hline & \multicolumn{2}{|c|}{ Disagree } & 0 & $0 \%$ & 6 & $3 \%$ & 6 \\
\hline & \multicolumn{2}{|c|}{ Don't know } & 2 & $5 \%$ & 12 & $6 \%$ & 14 \\
\hline & \multicolumn{2}{|c|}{ Strongly agree } & 22 & $55 \%$ & 70 & $38 \%$ & 92 \\
\hline \multicolumn{3}{|l|}{ Total } & 40 & $100 \%$ & 185 & $100 \%$ & 225 \\
\hline
\end{tabular}

Table 2: Explaining adherence among PLHIV using theory of planned behaviour.

goals and objectives was not associated with adherence to HAART $(\mathrm{P}=0.263)$. Also about $94 \%$ and $90 \%$ of PLHIV with non-adherent and adherent history respectively can meet set realistic goals/objectives for HAART adherence $(\mathrm{P}=0.994)$. Implying that ability to meet set realistic goals/objectives for HAART adherence had no effect on the actual adherence. About half (52\%) of the patients who are non-adherent have determinations to adhere while only $44 \%$ of those who are adherent claimed to have the determinations to adhere. More patients (55\%) who are not adherent to HAART had self-discipline to adhere to HAART while only $38 \%$ of those adherent to HAART had the self-discipline to adhere $(\mathrm{P}=0.655)$. Inferring that having self-discipline to adhere to HAART is not associated with HAART adherence.

\section{Explaining adherence using health believe model (HBM) (Table 3)}

About $58 \%$ and $46 \%$ of patients who were non- adherent to HAART and HAART-adherent respectively strongly believed that adherence to HAART improves HIV patent's health condition $(\mathrm{P}=0.004)$. While $66 \%$ of PLHIV who were HAART adherent believed that adherence to HIV medication is feasible in the Nigerian context only $48 \%$ of those nonadherent strongly held this believe too $(\mathrm{P}=0.00)$. About $68 \%$ of adherent patients and $63 \%$ of non-adherent patients agreed and strongly agreed respectively that refusal to adhere to HAART is a serious health risk for the HIV patient $(\mathrm{P}=0.00)$. About $46 \%$ and $50 \%$ of PLHIV who were HAART adherent and HAART non-adherent agreed and strongly agreed respectively that non-adherence to HAART was life threatening for the HIV patient $(\mathrm{P}=0.00)$. About $70 \%$ of PLHIV who were adherent to HAART agreed that non-adherence to HAART can lead to AIDS faster while only $35 \%$ of those who were non-adherent agreed with this statement $(\mathrm{P}=0.00)$. About $65 \%$ of PLHIV who were HAART adherent agree that the consequences of non-adherence to HAART were severe while only $40 \%$ of those not HAART adherent strongly held such believe $(\mathrm{P}=0.00)$. Almost $59 \%$ of HAART-adherent PLHIV agreed that adherence to HAART was beneficial while about $45 \%$ of those nonadherent to HAART strongly agreed that adherence to HAART was beneficial $(\mathrm{P}=0.00)$.

\section{Discussion and Conclusion}

All the 225 questionnaires administered were completely answered with the data cleaned and retrieved for analysis. There were more respondents who were female, married and had college education as the highest attained level of education. Such similar findings have been reported from other works done on adherence in the region [28]. Some African studies carried out among adult HIV patients in clinic settings also had higher ratio of female to male respondents $[29,30]$. More than fifty percent of the respondents were employed and most were Christians. This is contrary to national demographic survey which showed almost equal proportions of Christian and Muslims in the country and lower proportions of Nigerians with secondary and tertiary education [31]. Using the theory of planned behaviour (TPB) to explain HAART adherence among the clients, it was found that TPB model factors such as the ability to set realistic goals and objectives with respect to medication adherence and meet such goals do not have any significant association with adherence $(\mathrm{P}=0.001)$ among the PLHIV. 
Citation: Afe AJ, Motunrayo, Ogungbade GO (2017) Explaining Adherence to HAART among Patients Living with HIV/AIDS in Nigeria: Behavioral Theory Analysis. J AIDS Clin Res 8: 718. doi: 10.4172/2155-6113.1000718

Page 6 of 8

\begin{tabular}{|c|c|c|c|c|c|c|}
\hline \multirow{2}{*}{\multicolumn{2}{|c|}{$\begin{array}{l}\text { Believe that adherence to HAART improves HIV patent's health } \\
\text { condition }\end{array}$}} & \multicolumn{4}{|c|}{ Adherence to HART } & \multirow{3}{*}{$\begin{array}{c}\text { Total } \\
12\end{array}$} \\
\hline & & \multirow{2}{*}{$\begin{array}{c}\text { No } \\
4\end{array}$} & \multirow{2}{*}{$\begin{array}{c}\% \\
10 \%\end{array}$} & \multirow{2}{*}{$\begin{array}{c}\text { Yes } \\
8\end{array}$} & \multirow{2}{*}{$\begin{array}{c}\% \\
4 \%\end{array}$} & \\
\hline$P=0.004$ & Don't know & & & & & \\
\hline & Disagree & 2 & $5 \%$ & 4 & $2 \%$ & 6 \\
\hline & Agree & 10 & $25 \%$ & 86 & $46 \%$ & 96 \\
\hline & Strongly agree & 23 & $58 \%$ & 85 & $46 \%$ & 108 \\
\hline & Strongly disagree & 1 & $3 \%$ & 2 & $1 \%$ & 3 \\
\hline Total & & 40 & 100 & 185 & 100 & 225 \\
\hline \multirow{2}{*}{\multicolumn{2}{|c|}{ Adherence to HIV medication is feasible in the Nigerian context }} & \multicolumn{4}{|c|}{ Adherence to HAART } & \\
\hline & & No & $\%$ & Yes & $\%$ & Total \\
\hline \multirow[t]{5}{*}{$P=0.000$} & Agree & 11 & $28 \%$ & 122 & $66 \%$ & 133 \\
\hline & Disagree & 0 & $0 \%$ & 1 & $1 \%$ & 1 \\
\hline & Don't know & 12 & $30 \%$ & 10 & $5 \%$ & 22 \\
\hline & Strongly agree & 16 & $40 \%$ & 51 & $28 \%$ & 67 \\
\hline & Strongly disagree & 1 & $3 \%$ & 1 & $1 \%$ & 2 \\
\hline Total & & 40 & 100 & 185 & 100 & 225 \\
\hline \multirow{2}{*}{\multicolumn{2}{|c|}{ Refusal to adhere to HAART is a serious health risk for the HIV patient }} & \multicolumn{4}{|c|}{ Adherence to HAAR T } & \\
\hline & & No & $\%$ & Yes & $\%$ & Total \\
\hline \multirow[t]{5}{*}{$P=0.000$} & Don't know & 5 & $13 \%$ & 6 & $3 \%$ & 11 \\
\hline & Agree & 8 & $20 \%$ & 125 & $68 \%$ & 133 \\
\hline & Disagree & 1 & $3 \%$ & 5 & $3 \%$ & 6 \\
\hline & Strongly agree & 25 & $63 \%$ & 49 & $26 \%$ & 74 \\
\hline & Strongly disagree & 1 & $3 \%$ & 0 & $0 \%$ & 1 \\
\hline Total & & 40 & 100 & 185 & 100 & 225 \\
\hline \multirow{2}{*}{\multicolumn{2}{|c|}{ Non-adherence to HAART is life threatening for the HIV patient }} & \multicolumn{4}{|c|}{ Adherence to HAART } & \\
\hline & & No & $\%$ & Yes & $\%$ & Total \\
\hline \multirow[t]{5}{*}{$P=0.000$} & Don't know & 8 & $20 \%$ & 26 & $14 \%$ & 34 \\
\hline & Agree & 11 & $28 \%$ & 86 & $46 \%$ & 97 \\
\hline & Disagree & 0 & $0 \%$ & 4 & $2 \%$ & 4 \\
\hline & Strongly agree & 20 & $50 \%$ & 67 & $36 \%$ & 87 \\
\hline & Strongly disagree & 1 & $3 \%$ & 2 & $1 \%$ & 3 \\
\hline Total & & 40 & 100 & 185 & 100 & 225 \\
\hline \multirow{2}{*}{\multicolumn{2}{|c|}{ Non-adherence to HAART can lead to AIDS faster }} & \multicolumn{4}{|c|}{ Adherence to HAART } & \\
\hline & & No & $\%$ & Yes & $\%$ & Total \\
\hline \multirow[t]{3}{*}{$P=0.000$} & Don't know & 21 & $53 \%$ & 49 & $26 \%$ & 70 \\
\hline & False & 5 & $13 \%$ & 6 & $3 \%$ & 11 \\
\hline & True & 14 & $35 \%$ & 130 & $70 \%$ & 144 \\
\hline Total & & 40 & 100 & 185 & 100 & 225 \\
\hline Consequ & es of non-adherence to HAART are severe & & Adhe & AART & & \\
\hline & & No & $\%$ & Yes & $\%$ & Total \\
\hline$P=.000$ & Don't know & 7 & $18 \%$ & 11 & $6 \%$ & 18 \\
\hline & Agree & 13 & $33 \%$ & 120 & $65 \%$ & 133 \\
\hline & Disagree & 3 & $8 \%$ & 6 & $3 \%$ & 9 \\
\hline & Strongly agree & 16 & $40 \%$ & 45 & $24 \%$ & 61 \\
\hline & Strongly disagree & 1 & $3 \%$ & 3 & $2 \%$ & 4 \\
\hline Total & & 40 & 100 & 185 & 100 & 225 \\
\hline Adherenc & HAART is beneficial & & Adhe & AART & & \\
\hline & & No & $\%$ & Yes & $\%$ & Total \\
\hline$P=0.000$ & Don't know & 9 & $33 \%$ & 7 & $4 \%$ & 11 \\
\hline & Agree & 13 & $33 \%$ & 110 & $59 \%$ & 123 \\
\hline & Disagree & 0 & $0 \%$ & 1 & $1 \%$ & 1 \\
\hline & Strongly agree & 18 & $45 \%$ & 65 & $35 \%$ & 83 \\
\hline & Strongly disagree & 0 & $0 \%$ & 2 & $1 \%$ & 2 \\
\hline Total & & 40 & 111 & 185 & 100 & 225 \\
\hline
\end{tabular}

Table 3: Explaining adherence among PLHIV using health believe model (HBM).

Likewise other TPB factors like determination and self-discipline to adhere to medications (HAART) do not have statistical association with HAART adherence. On the other hand, Health Believe Model
(HBM) elements such as the belief that adherence to HAART improves HIV patent's health condition $(\mathrm{P}=0.004)$, adherence to HIV medication is feasible in the Nigerian context $(\mathrm{P}=0.00)$, refusal to adhere to 
Citation: Afe AJ, Motunrayo, Ogungbade GO (2017) Explaining Adherence to HAART among Patients Living with HIV/AIDS in Nigeria: Behavioral Theory Analysis. J AIDS Clin Res 8: 718. doi: 10.4172/2155-6113.1000718

HAART is a serious health risk for the HIV patient $(\mathrm{P}=0.00)$, nonadherence to HAART is life threatening for the HIV patient $(\mathrm{P}=0.00)$, non-adherence to HAART can lead to AIDS faster $(\mathrm{P}=0.00)$ and the consequences of non-adherence to HAART are severe $(\mathrm{P}=0.00)$ all show significant association with HAART adherence. Also significant statistical association was found between HAART adherence and other health believes like adherence to HAART is beneficial $(\mathrm{P}=0.00)$.

The theory of planned behaviour which has been used widely in health related study is appropriate to predicting behavior and retrospective analysis of behaviour [32,33]. Studies have shown that the TPB can be used to predict $20-30 \%$ of the change in health behaviour brought about through interventions. But a greater proportion of intention to alter health behaviour can be attributed to TPB. Both the attitudes towards the behaviour and perceived behavioural control have strong correlations with behaviour However only weak correlations have been demonstrated between behaviour and the subjective norms. This lack of strong correlation may be due to the study methodology used in those studies which if corrected appropriately may show strong relationships between behavior and subjective norms. The TPB may not be effective in planning and designing interventions that can result in behaviour change [34-36]. But it can be used to explain and predict likely behaviour by identifying particular influences on behaviour that could be targeted for change.

The HBM plays more descriptive than explanatory roles and does not often propose an approach for changing health-related actions but is most suited to explaining or predicting patterns of behaviour. For most effective use of the model it should be combined with other models that account for the environmental context and suggest strategies for change. Reviews of other works done on HBM have shown that it has weak predictive power, accounting for only about $10 \%$ of behavioural change [37]. Also, of all the HBM's constructs, perceived barrier is the most significant determinant of behavior [38]. Components and rules about their inter-relationships are not well defined, and (in common with other cognitive rational choice based models focused on the individual) that it does not include social or economic or unconscious (e.g. habitual) determinants of behaviour, which are generally considered to be at least as important as the personal cognitive factors covered by the model.

\section{References}

1. http://www.unaids.org/sites/default/files/media_asset/global-AIDSupdate-2016_en.pdf

2. http://www.unaids.org/en/dataanalysis/datatools/spectrumepp

3. National Agency for the Control of AIDS (NACA) (2014) Global AIDS Response Country Progress Report 2014.

4. http://www.ilo.org/wcmsp5/groups/public/---ed_protect/---protrav/---ilo_aids/ documents/legaldocument/wcms_146389.pdf

5. National Operational Plan for the Elimination of Mother to Child Transmission (eMTCT) of HIV in Nigeria 2015-2016. UNAIDS

6. National AIDS/STI Control Programme 2010-2014 Data (2010) NASCOP.

7. naca.gov.ng/fact-sheet-anti-retroviral-therapy-art-2016/

8. Simoni JM, Frick PA, Pantalone DW, Turner BJ (2003) Antiretroviral adherence interventions: A review of current literature and ongoing studies. Top HIV Med 11: $185-198$.

9. WilliamsA Friedland G (1997) Adherence, compliance and HAART. AIDS Clin Care 9: 51-56.

10. Murphy DA, Wilson CM, Durako SJ, Muenz LR, Belzer M, et al. (2001) Antiretroviral medication adherence among the REACH HIV-infected adolescent cohort in the USA. AIDS Care 13: 27-40.
11. Reddington C, Cohen J, Baldillo A, Toye M, Smith D, et al. (2000) Adherence to medication regimens among children with human immunodeficiency virus infection. Pediatr Infect Dis J 19: 1148-1153.

12. Steele RG, Anderson B, Rindel B, Dreyer ML, Perrin K, et al. (2001) Adherence to antiretroviral therapy among HIV-positive children: Examination of the role of caregiver health beliefs AIDS Care 13: 617-629.

13. WHO (2006) AIDS care consolidated guidelines on the use of antiretrovira therapy for HIV infection in adults and adolescents in resource-limited settings towards universal access: Recommendations for a public health approach World Health Organization, Geneva.

14. Bangsberg DR (2006) Less than 95\% adherence to non-nucleoside reversetranscriptase inhibitor therapy can lead to viral suppression. Clin Infect Dis 43 939-941.

15. Paterson DL, Swindells S, Mohr J, Brester M, Vergis EN, et al. (2000) Adherence to protease inhibitor therapy and outcomes in patients with HIV infection. Ann Intern Med 133: 21-30.

16. Paterson DL, Potoski B, Capitano B (2002) Measurement of adherence to antiretroviral medications. J Acquir Immune Defic Syndr 31: S103-S106.

17. Kim SH, Gerver SM, Sarah Fidler C, Helen Ward (2014) Adherence to antiretroviral therapy in adolescents living with HIV: Systematic review and meta-analysis, AIDS 28: 1945-1956.

18. Ajzen I (1991) The theory of planned behavior. Organizational behavior and human decision processes 50: 179-211.

19. Ajzen I (1985) From intentions to actions: A theory of planned behaviour 11-39

20. Fishbein M, Ajzen I (1975) Belief, attitude, intention and behavior: An introduction to theory and research.

21. Reading MA, Addison-Wesley, Hardeman W, Johnston $M$, Johnston $D$, et al. (2002) Application of the theory of planned behaviour in behaviour change interventions: A systematic review. Psychol Health 17:123-158.

22. Bandura $A$ (1986) Social foundations of thought and action

23. Bandura A (1997) Self-efficacy: The exercise of control, New York.

24. Armitage CJ, Conner M (2001) Efficacy of the Theory of planned behaviour: A meta-analytic review. Br J Soc Psychol 40: 471-499.

25. Harrison JA, Mullen PD, Green LW (1992) A meta-analysis of studies of the Health Belief Model with adults. Health Educ Res 7.

26. Hochbaum G (1958) Public participation in medical screening programs: A socio-psychological study.

27. Janz NK, Becker MH (1984) The Health Belief Model: A decade later. Health Educ $Q$ 11: 1-47

28. Lindsay JJ, Strathman A (1997) Predictors of recycling behaviour: An application of a modified health belief model. J Appl Soc Psychol, pp: 1799-1823.

29. Kasumu LO, Balogun MR (2014) Knowledge and attitude towards antiretroviral therapy and adherence pattern of HIV patients in southwest Nigeria. Int J Infect Control.

30. Potchoo Y, Tchamdja K, Balogou A, Pitche PP, Guissou IP, et al. (2010) Knowledge and adherence to antiretroviral therapy among adult people living with HIV treated in the health care centers of the association "Espoir Vie Togo" in Togo, West Africa, BMC Clin Pharmacol 10: 11.

31. Talam NC, Gatongi P, Rotich J, Kimaiyo S (2008) Factors affecting antiretrovira drug adherence among HIVIAIDS adult patients attending HIVIAIDS clinic at Mo Teaching and Referral Hospital, Eldoret, Kenya. East Afr J Public Health 5: 74-78.

32. National Population Commission (NPC) [Nigeria] (2013) Nigeria Demographic and Health Survey 2013 Preliminary Report Abuja, Nigeria: National Population Commission and Measure DHS, ICF International.

33. Taylor D, Bury M, Campling N, Carter S, Garfied S, et al. (2007) A review of the use of the Health Belief Model (HBM), the Theory of Reasoned Action (TRA) the Theory of Planned Behaviour (TPB) and the Trans-Theoretical Model (TTM) to study and predict health related behaviour change.

34. Armitage CJ, Conner M (2007) Social cognition models and health behaviour: A structured review. Psychol Health 15: 173-189.

35. Ajzen I, Madden TJ (1986) Prediction of goal directed behaviour: Attitudes intentions and perceived behavioural control. J Exp Soc Psychol 15: 173-189. 
Citation: Afe AJ, Motunrayo, Ogungbade GO (2017) Explaining Adherence to HAART among Patients Living with HIV/AIDS in Nigeria: Behavioral Theory Analysis. J AIDS Clin Res 8: 718. doi: 10.4172/2155-6113.1000718

Page 8 of 8

36. Armitage CJ, Sheeran P, Conner M, Arden MA (2004) Stages of change or changes of stage? Predicting transitions in transtheoretical model stages in relation to healthy food choice. J Consult Clin Psychol 72: 491-499.

37. Becker MH (1974) The health belief model and personal health behavior.
38. Munro S, Lewin S, Swart T, Volmink J (2007) A review of health behaviour theories: How useful are these for developing interventions to promote longterm medication adherence for TB and HIVIAIDS? BMC Public Health 7 : 104. 